\title{
ERRATUM
}

\section{Growth enhancement of soybean (Glycine max) upon exclusion of UV-B and UV-B/A components of solar radiation: characterization of photosynthetic parameters in leaves}

Kadur Guruprasad - Swapan Bhattacharjee · Sunita Kataria •

Sanjeev Yadav · Arjun Tiwari - Sanjay Baroniya · Abhinav Rajiv •

Prasanna Mohanty

Published online: 12 December 2007

(C) Springer Science+Business Media B.V. 2007

Erratum to: Photosynth Res (2007) 94:299-306

DOI 10.1007/s11120-007-9190-0

We regret errors in the names of the authors in the original article.

The online version of the original article can be found under doi: 10.1007/s11120-007-9190-0.

K. Guruprasad $\cdot$ S. Bhattacharjee $\cdot$ S. Kataria $\cdot$ S. Yadav

A. Tiwari $\cdot$ S. Baroniya $\cdot$ A. Rajiv $\cdot$ P. Mohanty $(\bowtie)$

School of Life Sciences, DAVV, Vigyan Bhawan, Khandwa

Road, Indore 452001, India

e-mail: photosis@rediffmail.com

K. Guruprasad

e-mail: knguruprasad@hotmail.com 